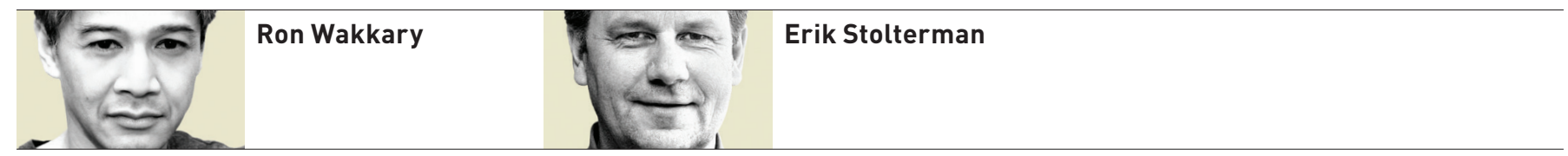

\title{
Distant Matters
}

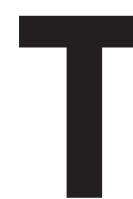

he authors of our cover story, Judith Olson and Gary Olson, discuss how over the past 20 years HCI researchers have conducted research on distance work. In that time, we have learned that with the right technologies and social practices, distance will matter, as the authors state, but "it will matter less.” The stressors of distance work - in particular, visibility, trust, cultural differences, and different time zones - will not disappear, but we know enough to make these issues manageable, and as a result, make distance work easier over time.
With a heavy heart, we give a final farewell to a longtime friend of Interactions, Gary Marsden. Matt Jones and Yvonne Rogers have written a heartfelt obituary for Gary (page 6), who tragically and unexpectedly died of a heart attack on December 27. Only recently, in the November-December 2013 issue, Gary retired his longstanding and influential Interactions forum, Under Development, which debuted in March 2006. In true fashion, Gary felt that the forum under his tutelage had done its best and it was time to make way for younger researchers to have the platform to advance HCI and design for development. Goodbye, Gary. We will miss you.

Last issue we introduced our new design and brand for Interactions. We hope you appreciate the new look and structure of the magazine-we look forward to any comments or suggestions you might have. We also invite you to write for Interactions through cover stories, feature articles, forum articles, Demo Hour, Day in the Lab, Confessions, and our blogs (interactions.acm.org/blog).

- Ron Wakkary and Erik Stolterman eic@interactions.acm.org

\section{The stressors of distance work-in particular, visibility, trust, cultural differences, and different time zones-will not disappear, but we know enough to make these issues manageable, and as a result, make distance work easier over time.}

